\title{
COEVOLUÇÃO E AS PRÁTICAS ISOMÓRFICAS DE GESTÃO: UM ESTUDO SOBRE OS PROCESSOS DE MUDANÇAS INSTITUCIONAIS NO INSTITUTO FEDERAL DE EDUCAÇÃO, CIÊNCIA E TECNOLOGIA DO RN
}

\author{
Maria Emília Santos Ferreira da Silva \\ Mestre em Administração \\ Professora do Instituto Federal de Educação, Ciência e Tecnologia do Rio Grande do Norte \\ Programa de Pós-graduação em Administração - Universidade Federal do Rio Grande do Norte (PPGA/UFRN) \\ Rua Alexandre Câmara, 1884/1302, Capim Macio, Natal-RN, Brasil. CEP: 59082-200 \\ Telefone: 558436422082 - E-mail: Emilia.santos@ifrn.edu.br; Memiliafer21@yahoo.com.br \\ Miguel Eduardo Moreno Añez \\ Professor Doutor em Administração \\ Programa de Pós-graduação em Administração - Universidade Federal do Rio Grande do Norte (PPGA/UFRN) \\ Av. Rodrigues Alves, 1271/302, Tirol, Natal-RN, Brasil. CEP: 59020-200 \\ Telefone: 558432012725 - E-mail: anez1957@ yahoo.com.br
}

\begin{abstract}
RESUMO
Este artigo propõe uma discussão sobre o processo de mudança institucional do IFRN, nos períodos de 1998 e 2008, sob a perspectiva coevolutiva em que os fatores institucionais e não-institucionais dos ambientes macro e micro mantêm uma relação de interdependência contínua com as organizações. Para corresponder aos pressupostos teóricos, o estudo recorre à trajetória histórica institucional, pois é nesse movimento recursivo que se consegue reintegrar a história, compreendendo que o momento atual é produto e efeito de mudanças institucionais em um determinado tempo e espaço, num processo de desestruturação, reestruturação, regeneração e evolução contínua. É preciso entender que esse movimento se dá numa relação de interdependência com o ambiente e perceber a impossibilidade de se estudar um fato deslocado do contexto que o determinou. Nesse sentido, o artigo objetiva estudar a dinâmica das práticas de gestão nos processos de mudança institucional do IFRN, referentes aos períodos 1998 e 2008, articulando as exigências do ambiente macro, as regulamentações governamentais às mudanças institucionais do ambiente micro. Diante da amplitude que o estudo sobre mutações apresenta, foi necessário delimitar a dinâmica das práticas isomórficas de gestão na instituição, nos respectivos processos de mudanças institucionais. Para a efetivação da pesquisa, adotou-se uma abordagem qualitativa, tendo como sujeitos os gestores desses processos de transformações institucionais. São feitos dois cortes transversais: a mudança de 1998 e a de 2008, articulando-os à história evolutiva da instituição e às exigências ambientais. A coleta de dados foi feita através de entrevistas semi-estruturadas, com questionamentos correspondentes aos objetivos do estudo. $\mathrm{Na}$ análise dos resultados foram constatadas as particularidades de cada mudança, a de 1998 (de ETFRN para CEFET-RN) e a de 2008 (de CEFET-RN para IFRN). Com relação aos respectivos contextos, evidenciou-se a importância da força dos gestores nos dois processos. Em 1998, a luta dos atores institucionais em favor dos princípios construídos em 1994 pela instituição ETFRN, que estavam em desacordo com as regulamentações governamentais da época; em 2008, a ação dos gestores como força normativa de gestão na implementação das mudanças, a retomada dos princípios pedagógicos, antes ignorados, e em consonância com as regulamentações governamentais. Serão discutidas as ações normativas de gestão, com relação às forças coercitivas do ambiente macro de cada contexto, delimitando-as com relação: à gestão da proposta de ensino, às formas de gestão e à mobilização dos gestores nos períodos de referência.
\end{abstract}

PALAVRAS-CHAVE: Práticas isomórficas. Relação de interdependência. Coevolução. 


\title{
COEVOLUTION AND THE ISOMORPHIC PRACTICES OF THE MANAGERS: A STUDY ON THE INSTITUTIONAL CHANGES PROCESS OF THE FEDERAL INSTITUTE FOR EDUCATION, SCIENCE AND TECNOLOGY OF RIO GRANDE DO NORTE
}

\begin{abstract}
This article proposes a discussion about the process of institutional change of IFRN, during 1998 and 2008 in the coevolutionary perspective on the institutional and non-institutional environment of macro and micro maintain an ongoing relationship of interdependence with the organizations. To match the theoretical assumptions, the study uses the historical path of institutional, because this movement is recursive which can reinstate the story, understanding that the present is product and effect of institutional changes in a given time and space in a process of disintegration, restructuring, regeneration and continuous development. You should understand that this movement is a relationship of interdependence with the environment and realize the impossibility of studying a fact moved from the context that determined. In this sense, the paper aims to study the dynamics of management practices in the processes of institutional change of IFRN, for the periods 1998 and 2008, articulating the requirements of the macro environment, government regulations to changing institutional environment system. Given the magnitude as the study of mutations shows, it was necessary to determine the dynamics of management practices at the institution isomorphic in their processes of institutional change. To carry out the research, we adopted a qualitative approach, having as subject the managers of these processes of institutional transformation. Two transverse cuts are made: the change in 1998 and 2008, linking them to the evolutionary history of the institution and environmental requirements. Data collection was done through semi-structured, with questions related to the study objectives. In the analysis of results were observed particularities of each change, of 1998 (ETFRN CEFET to-RN) and 2008 (from CEFE-RN for IFRN). With respect to their contexts, the study showed the importance of strength of the managers in both cases. In 1998, the efforts of institutional actors in favor of principles built in 1994 by institution ETFRN, which were at odds with government regulations at the time, in 2008 the share of managers, as normative force management in implementing the changes, the resumption of pedagogical principles, first ignored, and in line with government regulations. Will discuss the regulatory actions of management with respect to the coercive forces of the macro environment of each context, delimiting them with respect to: the management of the proposed teaching, forms of management and the mobilization of managers in reporting periods.
\end{abstract}

KEY-WORDS: Isomorphic practices. Interdependent relationship. Coevolution. 


\section{COEVOLUÇÃO E AS PRÁTICAS ISOMÓRFICAS DE GESTÃO: UM ESTUDO SOBRE OS PROCESSOS DE MUDANÇAS INSTITUCIONAIS NO INSTITUTO FEDERAL DE EDUCAÇÃO, CIÊNCIA E TECNOLOGIA DO RN}

\section{INTRODUÇÃO}

A perspectiva teórica coevolutiva traz, para os estudos organizacionais contemporâneos, uma nova ótica de análise dos fenômenos, pois as teorias organizacionais vigentes já não davam conta de explicá-los, tendo em vista a complexidade que o ambiente adquiriu num contexto de uma economia globalizada. Em um cenário, em que se configura o ambiente macro, é difícil estudar um fenômeno desarticulado de suas influências (sociais, políticas, econômicas ou outras) tendo em vista a relação contínua de interdependência com o ambiente.

São muitas as teorias que abordam o processo de mudança organizacional, porém, por considerarem apenas uma ótica de análise - chamada de teorias de lentes únicas - apresentam limitações com relação ao modo como as organizações evoluem e se adaptam ao longo do tempo, em relação ao contexto no qual estão inseridas. Os estudos sobre a coevolução, diferentemente das demais teorias, apresentam uma abordagem que integra várias perspectivas teóricas sobre mudança. Assim, a adoção dessa teoria para analisar os processos de mudança significa considerar várias lentes de análise (LEWIN e VOLBERDA, 1999)

Nesse sentido, essa teoria requer a consideração de três aspectos: a) o aspecto dialógico do estudo, permitindo manter a dualidade no seio na unidade - ou seja, para se compreender a realidade, é necessário entender que, diante de fatos novos, a realidade se desestrutura e se reestrutura continuamente, caracterizando as continuidades e descontinuidades, que, apesar de se apresentarem antagônicas, se complementam; b) o aspecto recursivo do estudo - ou seja, que a realidade mantém uma relação de interdependência e interação com o ambiente que a determina, expressando que "os produtos e os efeitos são, ao mesmo tempo, causas e produtos daquilo que os produziu" (MORIN, 2008, p. 108); e c) a visão hologramática do estudo, em que não apenas a parte está no todo, mas o todo está nas partes, sendo impossível compreender o objeto de estudo deslocado do contexto do qual faz parte (MORIN, 2008).

Essas considerações revelam novas formas de pensar e analisar as organizações, onde os fenômenos são estudados em sua dinâmica. A visão não linear e não determinista permite a leitura desses fenômenos de forma multidirecional, em que os fatores do ambiente macro interferem no ambiente micro (organizações), exigindo alterações neles mesmos. Estes, por sua vez, podem, através de ações gerenciais organizadas, corresponderem ou não às demandas ambientais. Daí a importância da ação dos gestores, considerada por essa abordagem, no processo de mudança. A esse respeito, Lewin, Long e Carrol (1999) comentam que as organizações, suas populações e seus ambientes são resultados interdependentes de ações gerenciais, influências institucionais e mudanças extra- institucionais (tecnológicas, sóciopolíticas e outros fenômenos ambientais).

A teoria da coevolução também considera a influência do papel das ideologias econômicas e políticas nos processos de mudanças institucionais; as relações de interdependência entre os ambientes macro e micro nos respectivos processos de mudança, o que direciona e justifica as ações dos gestores; e, também, a força do comportamento dos gestores como elemento essencial, no sentido de aderir e/ou resistir às mudanças.

Nesse contexto, este estudo busca esclarecer a dinâmica das práticas isomórficas de gestão no IFRN, nos períodos de mudanças institucionais citados, fazendo uma discussão sobre a teoria da coevolução, as práticas isomórficas da teoria institucional, a Educação Profissional e Tecnológica (EPT) no Brasil, enfatizando a relação de complementaridade e interação que permeia os ambientes das organizações de ensino, constituindo-se um conjunto de ações diretivas, influências institucionais e fenômenos ambientais. 


\section{A TEORIA DA COEVOLUÇÃO}

Os estudos sobre essa teoria resultaram de reflexões sobre: as interações entre as organizações; os ambientes em que elas se inserem; a forma como as organizações e os respectivos ambientes coevoluem; e sobre o papel da intencionalidade administrativa num ambiente altamente institucionalizado. Com esse entendimento, esses estudos apresentam os seguintes pressupostos: a) a compreensão de que o processo de coevolução organização/ambiente se constitui em movimentos de idas e vindas, de avanços e recuos na busca de uma melhor acomodação; b) o movimento recursivo da história, em que o momento presente se constitui, ao mesmo tempo, em causa e efeito daquilo que o produziu; c) e a impossibilidade de estudar os respectivos processos de mudanças de forma deslocada do contexto mais amplo.

Os trabalhos sobre a coevolução partiram de pesquisas científicas nas quais se constatou que, para entender o processo de tomada de decisões estratégicas dentro de uma organização, devem se considerar alguns aspectos referentes à organização como, o contexto sócio-político do ambiente institucional, sua origem e sua trajetória histórica.

No entanto, a idéia sobre a coevolução existe há mais de cem anos, nos estudos sobre a evolução humana, os quais entendem que os seres humanos não evoluem apenas pelo processo de seleção natural do ambiente do qual fazem parte. Eles evoluem por possuir a capacidade de aprender e pensar, o que lhes dá condições de amenizar os impactos ambientais que possam surgir (RODRIGUES e CHILD, 2008).

Nesse sentido, o desenvolvimento das organizações não se dá apenas por determinações ambientais, ou seja, numa visão determinista, mas que as organizações podem desenvolver práticas, novas ações e decisões, advindas de seus gestores organizacionais, para se adaptarem ao ambiente. Esse movimento, com o passar do tempo, possibilita às organizações, diferenciações em seus ambientes, tornando-as específicas em seu contexto. A concepção de interdependência ambiente/organização, portanto, só foi compreendida e reconhecida pelas teorias da organização posteriormente, representando a quebra de paradigma com relação ao determinismo ambiental (RODRIGUES, 2006).

Quanto à análise organizacional, a perspectiva coevolutiva apresenta vantagem diante de outras abordagens, devido à sua dinamicidade e às múltiplas dimensões de análises, tendo, como correntes influenciadoras, a ecologia das populações, a teoria institucional, a organização industrial, o custo de transação, a teoria comportamental da firma, a teoria evolutiva, a teoria baseada em recursos, a teoria contingencial, as capacidades dinâmicas, a aprendizagem organizacional e o equilíbrio pontual/ciclo de vida (LEWIN e VOLBERDA, 1999). Com essa compreensão, as organizações surgem e, com o passar do tempo, vão evoluindo; modificam-se, adquirem novos conhecimentos, técnicas, formas de gestão, novos formatos, a fim de se adaptarem e de se fortalecerem para concorrerem com o mercado. Caso contrário, elas podem deixar de existir.

As contribuições teóricas oferecidas por Lewin e Volberda (1999) à teoria da coevolução são importantes por abranger vários aspectos das demais teorias da organização. Suas principais características são: a) o foco de análise no ambiente como determinante do comportamento e desempenho da organização, ou nos atributos organizacionais como fatores determinantes; $b$ ) os atores organizacionais adotarem novas tendências, decorrentes das mudanças e demandas ambientais; c) a força das idéias, revelada por meio da ideologia dominante; d) as forças materiais, reveladas por meio dos avanços das tecnologias, das práticas administrativas, das competências humanas, dos recursos financeiros; e) a importância das condições iniciais da organização no processo de evolução (RODRIGUES e CHILD, 2008).

\section{O PROCESSO COEVOLUTIVO}

O processo coevolutivo, segundo Rodrigues e Child (2008), dá-se a partir da relação de interdependência contínua entre os ambientes macro e micro, onde as organizações, suas populações e seus respectivos ambientes são resultados interdependentes de ações administrativas, influências institucionais e mudanças extrainstitucionais. 
Esse movimento ocorre em um contexto institucionalizado, onde há relevância de fatores e situações do ambiente macro, que afetam as organizações no ambiente micro. No ambiente macro, os fatores não institucionais ou extrainstitucionais, referentes ao contexto global, independem do controle institucional, porém influenciam na dinâmica das organizações; os fatores institucionais influenciam mais diretamente na dinâmica organizacional a nível micro, exigindo que as organizações se reestruturem e se reorganizem. No entanto, a evolução no contexto global não sofre influência do regime institucional do nível micro, mas, sim, interfere nele.

Entretanto, as dinâmicas ocorridas em cada setor da sociedade resultam em certo perfil de desempenho organizacional. As do nível micro impactam sobre as do nível macro, numa relação de interdependência e retroalimentação, ou seja, o seu desempenho alimenta a economia, como um todo, e se desenvolve, tanto por meio de ganhos de eficiência, de melhorias dos serviços, quanto no atendimento às expectativas de diversos grupos da sociedade macro. Se a avaliação do desempenho do setor não for satisfatória, mudanças devem ocorrer para superar as fragilidades não compatíveis com os interesses dos grupos majoritários (RODRIGUES e CHILD, 2008).

As regulamentações específicas aplicadas no setor micro, referentes aos diferentes segmentos de mercado e setores de serviços são estabelecidas pelo nível macro; as regulamentações governamentais, que afetam as organizações e instituições, impõem limites e determinam até que ponto as forças não institucionais podem atuar no setor nacional.

O esquema teórico coevolutivo, ilustrado na figura a seguir, explicita a visão multidimensional e não linear oferecida pela teoria da coevolução.

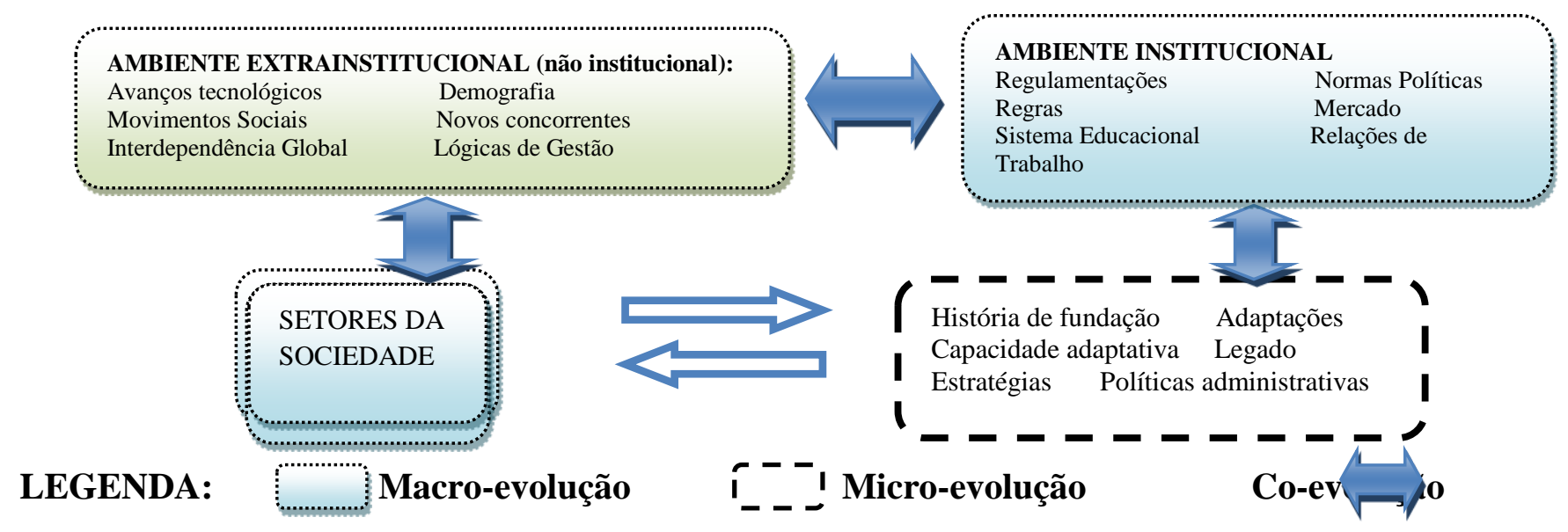

FIGURA 1: O processo de Coevolução das organizações, as esferas da sociedade e seus ambientes FONTE: Rodrigues, S e Child, J (2006)

Os pontos de coevolução, demonstrados pelas setas apontadas para os dois lados, evidenciam a interação de mão dupla, em que organizações, inseridas em um determinado mercado, produzem bens e serviços, tanto para atender às demandas ambientais, como para produzir todos os elementos necessários à organização e à sua própria sobrevivência (RODRIGUES e CHILD, 2008). A esse respeito, Morin (2008) afirma que, ao produzirem bens e serviços, as organizações se auto-organizam, se automantém, e, se necessário, se automodificam. Nesse processo, elas se autodesenvolvem, gerando o processo de coevolução.

Quando surgem situações inesperadas, as organizações são pressionadas a empreender mudanças e adaptações evolucionárias para continuar o processo de evolução. A dimensão do impacto das mudanças - que a evolução global dos fatores não institucionais acarreta -, em um dos setores da sociedade brasileira, vai depender da 
representatividade desse setor no regime institucional ${ }^{1}$ (SAUNDERS, 1994 apud RODRIGUES e CHILD, 2008). Os fatores institucionais dão relevância aos regimes de cada setor da sociedade, modificando as dinâmicas das organizações, exigindo modificações e ajustes para conseguirem adaptações evolucionárias, ou seja, novos empreendimentos, novos conhecimentos, novas práticas gerenciais nas organizações em que estão inseridas.

Stinchcombe (1965) apud Rodrigues e Child, (2008), afirma que as organizações suportam mudanças subsequentes por duas razões: a) a identidade e a imagem pública da organização, com relação à sua criação, continuarão sendo significativas para as pessoas que participam da organização e acompanham as mudanças subsequentes; b) o sucesso da organização centra-se na habilidade dos gestores para conseguir adaptar-se e aprender, e, isso dependerá, essencialmente, da qualidade dos recursos da organização e das possibilidades oferecidas para tal.

Sobre essa perspectiva, os estudos acerca da evolução organizacional apontam que a continuidade coexiste com a mudança, num movimento recursivo. As fases de equilíbrio organizacional podem ser afetadas em alguns momentos e/ou aspectos, repercutindo nos conhecimentos acumulados ou nas competências desenvolvidas; porém, a sua evolução mantém-se com o passar do tempo. Portanto, a coevolução discute as relações de interdependências entre os diferentes processos internos da organização e a importância dessas interações, já que o ambiente pode mediá-las, para compreender como as organizações evoluem,

Dessa forma, as organizações, em geral, estão sujeitas à evolução da política social e, ao mesmo tempo, seus atores possuem mais liberdade para participar e influenciar a evolução dessas políticas. Com relação aos processos políticos, Redding apud Rodrigues (2006) afirma que as lógicas ideacionais e materiais se constituem em elementos fundamentais na condução das mudanças organizacionais.

\section{PRÁTICAS ISOMÓRFICAS NO PROCESSO COEVOLUTIVO}

Outro fator relevante refere-se às ações administrativas de cada organização que, por sua vez, podem atingir níveis de desempenhos diferentes. Estudos desenvolvidos sobre as práticas isomórficas ${ }^{2}$ (DIMAGGIO e POWELL, 1991 apud RODRIGUES e CHILD, 2008), demonstram a importância do isomorfismo na conformação e homogeneidade das organizações em seus ambientes, com relação às demandas advindas das pressões institucionais. Esse processo se dá por meio dos mecanismos isomórficos que se caracterizam como forças coercitivas, miméticas e normativas, que são essenciais no processo de evolução e sobrevivência das organizações.

A força coercitiva significa que a organização, num dado campo organizacional já existente, tende a ser similar por causa da conformação organizacional às exigências do Estado. A força mimética resulta das tentativas organizacionais de imitar os processos, estruturas ou práticas das outras organizações como uma maneira de enfrentar um ambiente incerto. A força normativa está associada à profissionalização, um processo de definição de condições, métodos, padrões e fronteiras das práticas profissionais (DIMAGGIO e POWELL, 1983 apud MACHADO-DA-SILVA; VIZEU, F, 2007).

De acordo com Machado-da-Silva, Fonseca e Crubellate (2009), o peso de cada um desses três mecanismos isomórficos, em processos de transformação organizacional, depende da situação e história sociocultural de cada sociedade. Nessa perspectiva, em um ambiente com fortes restrições, as ações administrativas são mais limitadas, podendo ocorrer uma inércia estrutural ${ }^{3}$, administrativa (OLIVER, 1992 apud RODRIGUES e

\footnotetext{
${ }^{1} \mathrm{O}$ termo regime refere-se ao domínio institucional instituído no setor e a sua estrutura de concorrência. O regime é, geralmente, refletido nos objetivos e políticas encontradas dentro de cada setor que, por sua vez, virão a tipificá-lo à medida que há pressões mais significativas na população das organizações existentes (RODRIGUES e CHILD, 2008).

${ }^{2}$ Práticas isomórficas - são práticas de gestão que visam à conformidade e à homogeneidade organizacional em seu ambiente; caracterizam-se como forças coercitivas, normativas e miméticas.

${ }^{3}$ A Teoria da Inércia Estrutural, apresentada por Hannan e Freeman (1977) apud Wood Jr (2008), direciona para duas questões principais: até que ponto as organizações podem mudar? A mudança é benéfica para as organizações? Os autores propõem ademais que,
} 
CHILD, 2008). Isso dificulta a ação dos gestores para criar intenções, nova formas e práticas organizacionais, que oportunizem maior disponibilidade de recursos e aumentem a sua legitimidade administrativa.

Quando a organização lidera na qualidade e/ou na inovação de suas políticas e práticas ou quando domina o setor de que faz parte, ela pode reter o potencial e influenciar-lhe as condições. Essas circunstâncias realçam a capacidade dos gestores de se integrarem nas redes que os ligam aos circuitos de tomadas de decisão (CLEGG, 1989 apud RODRIGUES e CHILD, 2008).

Rodrigues e Child (2008) mencionam a possibilidade de os gestores fazerem opções estratégicas, buscando influenciar ou alcançar adaptações em ambientes específicos e, consequentemente, em ambientes mais amplos. Para isso, eles precisam ser informados das oportunidades de ação e das restrições ambientais que as circunstâncias externas apresentam sob seu espaço de ação. Os desempenhos organizacionais, portanto, juntamente com as habilidades administrativas, produzem impactos ambientais, nos quais as organizações se inserem. A repercussão ambiental pode se reproduzir em interesses políticos no interior das organizações, referentes ao processo evolutivo.

Nesse contexto, tanto o desempenho do nível macro como o desempenho no nível micro podem demandar mudanças de regime político. O regime em poder articula a ideologia social e econômica, a nível macro, dominando a política nacional. Essa ideologia e as políticas que lhe são associadas dão origem ao regime institucional que governa o setor, tornando complexo o ciclo evolutivo do ambiente das organizações. Com esse entendimento, geralmente o nível do desempenho econômico global de um país legitima a ideologia sociopolítica dos interesses majoritários se for satisfatório e, tira-lhe a legitimidade, se for insatisfatório.

\section{A EDUCAÇÃO PROFISSIONAL NO BRASIL E AS INSTITUIÇÕES DE EDUCAÇÃO PROFISSIONAL NUMA TRAJETÓRIA COEVOLUTIVA}

A Educação Profissional (EP) no Brasil pode ser analisada sob vários aspectos - histórico, político, legal, econômico e social. A relação de interdependência, que esses aspectos mantêm entre si, faz com que a abordagem de um contemple aspectos significativos dos demais. No entanto, é necessário entender que, em diferentes contextos sociais, as ações e estratégias tomadas, por vários dirigentes da nação, tiveram papel importante na construção do processo histórico, no qual se deu a evolução da prática da EP na sociedade. Este estudo se limitará a descrever os momentos considerados mais relevantes na história da EP, na intenção de articular as mudanças institucionais dos ambientes - o macro com a educação profissional. Dessa forma, com base nos pressupostos teóricos da teoria da coevolução, não se pode compreender a EP no Brasil desarticulada do contexto histórico, econômico e social mais amplo.

Na abordagem do processo histórico da EP no Brasil, os pressupostos teóricos da teoria da coevolução oferecem subsídios para compreender como os fatores do ambiente institucional macro interferem no ambiente micro, numa relação de interdependência. Esse movimento se dá de forma contínua, com avanços e recuos, por meio do qual ocorre o processo coevolutivo das organizações nos ambientes.

Dessa forma, não se pode conceber a evolução da EP no Brasil e dos Institutos Federais de Educação, Ciência e Tecnologia, de forma desarticulada. Eles fazem partem de uma mesma realidade multifacetada em que as partes se complementam, configurando um movimento contínuo de interdependência. Nessa relação de interdependência e complementaridade, a teoria coevolutiva defende a necessidade de as organizações, por meio de seus gestores, desenvolverem práticas isomórficas a fim de conseguir adaptarem-se às demandas do ambiente. Dessa forma, preservando sua existência e, ao mesmo tempo, fortalecendo-se e evoluindo, enquanto acompanham o processo de transformação da sociedade de ordem econômica, social e política. Nessa

além de mudar em função da estrutura organizacional, as pressões inerciais variam com o tamanho e a idade organizacional. Afirmam que, dentro de certas condições, organizações com características inertes têm mais chance de sobreviver (Clegg, et al 2006). Essa teoria descreve as organizações como entidades relativamente inertes para as quais a resposta adaptativa não é somente difícil e pouco frequente, mas, perigosa (RODRIGUES e CHILD, 2008).

HOLOS, Ano 26, Vol. 4 
perspectiva, para se entender a EP do momento atual, faz-se necessário conhecer todos os fatores que a determinaram, em sua história, em um estudo recursivo, onde a ordem e a desordem estão presentes em todo o contexto, caracterizando a continuidade e descontinuidade dos processos ao longo do tempo.

Nesse contexto, no Brasil, a partir dos anos 80, o capitalismo entra em crise com o enfraquecimento do modelo taylorista-fordista no processo de organização das relações de produção. Consequentemente, a educação profissional em vigor, responsável pela formação profissional, já não conseguia responder às necessidades do mundo de trabalho. Com essa preocupação, o governo promove políticas de ajuste estrutural entre os países mais afetados pelo desequilíbrio econômico. Essas políticas incluem a redução do papel do Estado, que antes tinha um papel central no desenvolvimento do capitalismo; uma maior participação do setor privado; a realização de reformas administrativas; estabilização fiscal e monetária; redução dos créditos internos e das barreiras de mercado.

As transformações nos meios de produção e das relações de trabalho na década de 90 , mais especificamente, intensificaram-se mundial e nacionalmente, ampliando a extensão do ambiente a nível macro, exigindo novas mudanças na educação. Nesse contexto, a promessa integradora da escola é substituída pela promessa da empregabilidade ${ }^{4}$. Assim, sob uma nova base científica e tecnológica, exige-se uma reorganização da educação básica, de formação profissional, qualificação e requalificação, que desenvolvam habilidades básicas no plano do conhecimento, das atitudes e dos valores, produzindo competências para a gestão da qualidade, para a produtividade e competitividade e, consequentemente, para a "empregabilidade", preparando o trabalhador para ser flexível às mudanças solicitadas pelos empregadores (LOMBARDI; SAVIANI; SANFELICE, 2002).

Essas transformações no modo de produzir representam grandes desafios para as escolas técnicas e de EP, que, com o avanço do conhecimento e o desenvolvimento das tecnologias, são pressionadas à reestruturação e reorganização, adquirindo novas configurações para responderem às demandas impostas pelo ambiente macro. A rapidez das inovações ambientais, frente à relação de interdependência entre os ambientes macro e micro, evidencia-se fortemente diante da necessidade de as organizações de ensino prepararem a mão-de-obra para assumir funções nas indústrias, cabendo à educação, reorganizar-se para atender às necessidades de qualificação dos trabalhadores para o mundo do trabalho. As escolas passam de uma lógica da integração, em função das necessidades e demandas coletivas, para uma lógica econômica estritamente privada e conduzida pela ênfase nas capacidades e competências que cada indivíduo deve adquirir no mercado educacional, para atingir uma melhor posição no mundo do trabalho.

Nesse contexto, as mudanças qualitativas, para o alcance da competitividade no mercado, exigem mudanças profundas na educação, tornando-a, cada vez mais, atrelada ao mundo do trabalho e da produção; a autonomia ganha importância, deslocando o eixo do poder e o lócus da decisão. Esse cenário também implica mudanças na gestão, requerendo novos modelos fundamentados na flexibilidade administrativa, na descentralização e na desconcentração dos poderes de decisão, reestruturando a capacidade de cooperação e planejamento.

Em 1996, com a promulgação da nova Lei de Diretrizes e Bases da Educação Nacional - LDBEN, Lei ${ }^{\circ}$ 9394/96, para reestruturação de toda a educação brasileira e, por meio do decreto lei 2.208/97, institui-se a elaboração de um Projeto Pedagógico (PP), que deveria ser construído separadamente - um para o ensino médio e outro para os cursos técnicos, em todas as escolas do país. Esse projeto deveria ser acompanhado e avaliado periodicamente para verificação da sua qualidade, representando, assim, consequencias para as instituições de ensino profissional e para os sistemas públicos de educação que mantinham cursos de nível técnico no Brasil. O advento dessa nova lei traz consequências para as instituições de educação profissional: a separação do ensino médio da formação profissional de nível técnico e a concepção de currículo por competências.

\footnotetext{
4 "A empregabilidade é que articula e oferece coerência aos três elementos que poderiam permitir superar a crise do desemprego mediante uma dinamização dos mercados de trabalho: a redução dos encargos patronais, a flexibilização trabalhista e a formação profissional permanente" (LOMBARDI; SAVIANI; SANFELICE, 2002, p.52)
} 
Outra consequência desse decreto lei é a criação novos cursos em nível técnico com duração aproximada de 18 meses em áreas profissionais. As ofertas formativas se expandem, é incluída a oferta de EP nos níveis básico, técnico e tecnológico, além do ensino médio. As instituições de EPT começam a atuar no ensino de $3^{\circ}$ grau, com a oferta de cursos de graduação tecnológica, ampliando-se, posteriormente, para os cursos de formação de professores e as licenciaturas.

Além disso, a falta de preparação dos profissionais para trabalhar com essas propostas curriculares, orientadas a partir de currículos por competências, habilidades e bases tecnológicas, definidas de acordo com um perfil profissional de conclusão e com a realidade do contexto socioeconomico e político, contribuiu para que as instituições vivenciassem dificuldades para a efetivação das suas ações. Porém, mesmo diante dessas dificuldades, o processo de "cefetização" se inicia, expandindo as ofertas formativas da escola.

Em 2008, o CEFET/RN, prestes a completar seu primeiro centenário, em 23 de setembro de 2009, adquirem nova configuração, por meio do decreto 6986/09, que regulamenta a lei $\mathrm{n}^{\circ} 11.892$, de 29 de dezembro de 2008 , e transformam-se em Institutos Federais de Educação, Ciência e Tecnologias. Com base nesses dispositivos legais, foram estabelecidas as diretrizes para essa reorganização, de modo a favorecer a sua atuação integrada e referenciada regionalmente, ofertando ensino de forma verticalizada.

Nessa expansão, foram criados 354 Institutos Federais em todas as mesorregiões do país, o que exige das escolas nova forma de atuação, que desenvolva um Projeto Político Pedagógico (PPP) mais arrojado, verticalidade da oferta de educação profissional e tecnológica, articulação com o ensino regular, aumento da escolaridade do trabalhador, interação com o mundo do trabalho e com as ciências e apoio à escola pública (BRASIL, 2007, p. $33)$.

\section{CONSIDERAÇÕES METODOLÓGICAS}

A escolha do IFRN como lócus da pesquisa se deu por algumas razões tais como: ser uma instituição de EPT de reconhecimento nacional; a facilidade no acesso aos profissionais e, por conseguinte, aos documentos institucionais; e o momento representativo institucional - o seu centenário. Assim, parte-se de um estudo de caso, que objetiva contribuir com o conhecimento que se tem do fenômeno individual, organizacional, social, político e de grupo, além de outros fenômenos relacionados (YIN, 2005). Segundo o autor, "o estudo de caso representa a estratégia preferida quando se colocam perguntas do tipo 'como' e 'por quê', quando o pesquisador tem pouco controle sobre os acontecimentos e quando o foco se encontra em fenômenos contemporâneos inseridos em algum contexto da vida real" (YIN, 2005, p. 19).

Para fins desse estudo, foi adotada uma abordagem qualitativa, por abrir a possibilidade de enfatizar, no registro dos dados coletados, conteúdos significativos para a compreensão do objeto de estudo desta pesquisa. Usando-se o modelo qualitativo, descreve-se a realidade encontrada, possibilitando uma análise com maior profundidade, ou seja, o estudo expõe características de determinada população ou de determinado fenômeno, porém não tem o compromisso de explicar os fenômenos que descreve, embora sirva de base para tal explicação (VERGARA, 2007).

Para tanto, foram feitos dois cortes transversais, um em 1998 e outro em 2008. A pesquisa buscou, na literatura, orientações e percepções de vários teóricos sobre o procedimento metodológico a ser adotado. O percurso teórico-metodológico, atrelado ao problema e aos objetivos de pesquisa, juntamente com as etapas desenvolvidas e os procedimentos metodológicos, correspondem aos objetivos do estudo. Na formulação das questões de pesquisa, buscou-se manter a coerência com a abordagem teórica, tendo em vista a necessidade de assegurar um rigor teórico na apreensão e análise dos dados coletados. Os sujeitos da pesquisa foram os gestores que participaram das referidas mudanças institucionais, que somaram 20 (vinte), porém, devido à quantidade de repetições obtidas em seus relatos, foi adotada a técnica de "fechamento amostral", com base na saturação, ou

\footnotetext{
${ }^{5}$ Fechamento Amostral - É usado para estabelecer ou fechar o tamanho final de uma amostra em estudo, interrompendo a captação de novos componentes. O fechamento amostral por saturação teórica é operacionalmente definido como a suspensão de inclusão de novos
} 
seja, quando se exige do pesquisador a clareza nos critérios para interromper a seleção de casos novos, tornandoos inteligíveis aos leitores (FONTANELLA, B. J; RICAS, J; TURATO, E. R. 2008). Isso se dá por redundância de informações ou saturação. Assim sendo, dos dados coletados, foram selecionados 12 (doze) relatos considerados os mais significativos.

Cabe ressaltar que foram priorizados os gestores que tiveram participações efetivas nos dois processos. Os nomes dos gestores entrevistados estão preservados, sendo referenciados por um código formado pela consoante G, acrescida de um numeral. A partir das falas foram construídas as categorias de análises. Segundo Bardin (2002), a categorização baseia-se em operações de desmembramento do texto em unidades, ou seja, descobrir os diferentes núcleos de sentido que constituem a comunicação e, posteriormente, realizar o seu reagrupamento em classes ou categorias. Essas, posteriormente, são selecionadas conforme os ambientes macro e micro, abordados pela teoria co-evolutiva. Como se trata de categorias amplas, elas foram divididas em subcategorias.

\begin{tabular}{|c|c|c|}
\hline NÍVEL DE ANÁLISE & CATEGORIAS & SUBCATEGORIAS \\
\hline \multirow[t]{3}{*}{ MACRO } & PROCESSO DE GLOBALIZAÇÃO & $\begin{array}{l}\text { Novas demandas sociais e de mercado; } \\
\text { Novas formas de gestão; } \\
\text { Novas relações de trabalho, demandando } \\
\text { novo perfil de profissional. }\end{array}$ \\
\hline & $\begin{array}{l}\text { AVANÇO DAS CIÊNCIAS E DO } \\
\text { CONHECIMENTO }\end{array}$ & $\begin{array}{l}\text { Novo direcionamento da formação } \\
\text { profissional. }\end{array}$ \\
\hline & ESTRUTURA DE GOVERNO & $\begin{array}{l}\text { Política de governo; } \\
\text { Regulamentação governamental; } \\
\text { Educação Profissional. }\end{array}$ \\
\hline \multirow{3}{*}{ MICRO } & HISTÓRICO INSTITUCIONAL & Caracterização institucional. \\
\hline & GESTÃO & $\begin{array}{l}\text { Proposta de ensino; } \\
\text { Formas de gestão; } \\
\text { Mobilização dos gestores. }\end{array}$ \\
\hline & IDENTIDADE & $\begin{array}{l}\text { Legitimidade; } \\
\text { Política de governo; } \\
\text { Expansão institucional. }\end{array}$ \\
\hline
\end{tabular}

QUADRO 1: Quadro das categorias de análise.

FONTE: dados do estudo, 2010.

Em seguida são discutidos os resultados e as considerações finais pertinentes ao estudo, todos articulados aos pressupostos teóricos da teoria adotada.

\section{DESCRIÇÃO DOS RESULTADOS DO CASO IFRN}

A análise de conteúdo foi feita por meio da análise dos dados coletados. Para Bardin (2002, p. 38), a análise de conteúdo é "[...] um conjunto de técnicas de análise das comunicações que utiliza procedimentos sistemáticos e objetivos de descrição do conteúdo das mensagens", ou seja, um conjunto de informações é reduzido a um conjunto de categorias. No entanto, como algumas categorias selecionadas foram bastante amplas, houve a necessidade de dividi-las em subcategorias para assegurar ao pesquisador o foco e os objetivos do estudo. As categorias macro foram retiradas dos pressupostos teóricos coevolutivos; as categorias micro, dos objetivos do estudo; as subcategorias foram construídas a partir das falas dos entrevistados, como demonstra o quadro das categorias acima.

participantes, quando os dados obtidos passam a apresentar, na avaliação do pesquisador, uma certa redundância ou repetição, não sendo considerado relevante persistir na coleta de dados (FONTANELLA, B. J; RICAS, J; TURATO, E. R. 2008). 


\section{OS FATORES MACRO E AS ORGANIZAÇÕES}

A relação de interdependência dos fatores macro nas organizações revela a força coercitiva do processo de globalização que impõe às instituições de EPT, especificamente o IFRN, rever seus princípios e suas práticas frente às exigências do mundo do trabalho, a fim de responder às exigências do ambiente macro. Além disso, o aprofundamento do capitalismo, no contexto de uma economia globalizada, com novo modo de produção e de relações de trabalho, provoca novas demandas à educação profissional e tecnológica, exigindo um novo profissional, novas ofertas formativas nas instituições de ensino e profissionais com maior competência e habilidades para lidarem com questões emergenciais. Isso exige reestruturações e reorganizações da gestão na proposta de ensino como também nas suas práticas de gestão. A esse respeito um gestor comenta,

\footnotetext{
"A instituição realmente não tem como ficar imune a esse movimento, porque ela trabalha com pessoas para trabalharem. $\mathrm{O}$ nosso diferencial é esse, nós não formamos uma pessoa para ser cidadão sem emprego" (G3).

"Então, do ponto de vista institucional, as mudanças no mundo implicam em mudanças das políticas de governo. E, com relação à educação, isso implicaria, obviamente, em mudanças no nível de formação das pessoas, a formação profissional mais especificamente"(G2).
}

É evidente a repercussão dos avanços das ciências, do conhecimento e das tecnologias, principalmente, a partir do final do século XX e início do século XXI, na EPT. Nesse caso, particularmente no IFRN, de forma coercitiva, pois se modificam os processos de trabalho e, consequentemente, as demandas correspondentes a esse setor. Quanto à gestão, o grande desafio da mudança institucional de 2008 se traduz na sua descentralização que, enquanto CEFET-RN, era centralizada na unidade sede em Natal/RN.

Com relação à categoria estrutura de governo, percebe-se a força coercitiva que as regulamentações governamentais possuem nas instituições de EPT, consequentemente, no IFRN, em toda sua trajetória. Outro aspecto relevante é a diferença significativa da atuação dos governos federais nos dois períodos de mudanças institucionais, em 1998 e 2008. No primeiro, percebe-se uma política de estado mínimo que dificultava a expansão da EPT com uma política educacional restritiva; no segundo período, a partir de 2003, uma política de governo que fomenta a expansão da EPT, atingindo de forma equânime as várias regiões do país. Nesse sentido, para atender as exigências dos fatores a nível macro, a política de governo age de forma coercitiva nas instituições de EPT, no IFRN, exigindo mudanças e reestruturações.

No que diz respeito à categoria do ambiente micro, está compreendido o histórico da instituição, discutido rapidamente na evolução da $\mathrm{EP}$ no Brasil, assim como os aspectos relacionados à gestão e às preocupações com relação à identidade organizacional. Nesse item foram constatadas mudanças significativas no fazer da instituição, expressas pelos gestores, principalmente em 2008.

\section{GESTÃO COM RELAÇÃO À PROPOSTA DE ENSINO}

O processo de transformação de 1998, na verdade, iniciou-se em 94 , pois a mudança não ocorreu de repente e, sim, como parte de um processo. Em 94, a instituição era basicamente de ensino técnico. Nessa época, uma equipe de gestores (docentes e administrativos) mobilizou-se para repensar o PPP da escola, no sentido de reorganizá-lo para atender às necessidades de qualificação dos trabalhadores para o mundo do trabalho. Essa ação visou rever a proposta curricular, defasada diante das novas demandas e das transformações ocorridas no mundo do trabalho, como também evidenciou, para a sociedade, a contribuição da ETFRN enquanto instituição de ensino profissional. Junto a isso havia o desejo institucional em se transformar em CEFET-RN, como enfatiza um dos entrevistados,

A mudança institucional de ETFRN pra CEFET (1998) se deu, oficialmente, em 1998. Em 1994 começou-se a discussão de mudança. Quando ocorreu essa evolução institucional, a mudança já 
havia escolas técnicas no Brasil, que já eram CEFETs, como a do Paraná, que já atuava na educação profissional superior; e Rio de Janeiro e Minas Gerais, que estavam passando a atuar no nível superior. Assim, outras escolas técnicas passaram a pleitear essa mudança. A intenção de mudança surgiu com... a partir da mudança dessas escolas ${ }^{6}(\mathrm{G} 9)$.

A ação dos gestores, nesse momento, caracteriza a força normativa da gestão, objetivando a expansão e novas conquistas institucionais, como também o fortalecimento e reconhecimento institucional na sociedade. $\mathrm{O}$ comportamento dos gestores revela a força da gestão na instituição pelo seu fortalecimento. Foram feitas reflexões, discussões e análises internas, tendo como referência a realidade do sistema produtivo, com base no tipo de formação oferecida pela instituição para, a partir daí, desenvolver uma proposta pedagógica. Essa proposta deveria apresentar uma visão mais ampla de educação profissional, não só ofertando a formação para o aluno adequar-se ao mundo do trabalho, mas também a possibilidade de construir e elaborar o seu conhecimento. Dessa forma, o discente parte de seu próprio mundo, contribuindo, atuando e influenciando na sociedade. Nesse processo, é dada a oportunidade de ingressar, tanto no mundo do trabalho como de dar continuidade à carreira acadêmica. Isso tudo em um só sentido: o de formar não apenas o técnico competente, mas o cidadão engajado dentro de um contexto, num dado espaço e num dado tempo.

Essa formação era desenvolvida articulando o ensino médio ao técnico, ou seja, a formação técnica integrada à formação propedêutica. Esse trabalho exigiu muitos esforços dos gestores durante a sua implementação, no sentido de fazer o papel de "animadores" desse processo e de disseminá-lo pela instituição. Esse trabalho dos gestores resultou no PPP que se tornou reconhecido nacionalmente e adotado como modelo tanto pelo MEC como também por outras instituições de EPT do Brasil. A ETFRN, assim, passa a ser reconhecida nacionalmente pelo seu trabalho de qualidade.

No entanto, em 1997, com a implementação do decreto 2.208/97, como força coercitiva do ambiente institucional, fica regulamentada a separação do ensino médio da formação técnica e a criação de cursos tecnológicos. As ofertas formativas se expandem, sendo incluída a oferta de educação profissional nos níveis básico, técnico e tecnológico e nos CEFET. No CEFET-RN, inicia-se a atuação no ensino de $3^{\circ}$ grau, com a oferta de cursos de graduação tecnológica. Essa oferta visava a uma formação mais curta, fragmentada e especialista, aproximadamente de 18 meses em áreas profissionais.

Na visão dos gestores, a proposta do decreto 2.208/07 defendia uma formação descartável e, consequentemente, não atendendo às demandas do mundo produtivo por uma formação de qualidade. Além disso, alertam para outro fator decorrente desse decreto: a falta de interesse da política de governo em investir na EPT, querendo transferir a responsabilidade dessas instituições para as unidades federativas. Isso gerou grande insatisfação nos atores institucionais com a política educacional vigente para a EP, desencadeando, na instituição, um movimento de resistência e luta interna, por meio do qual os servidores se uniram pela não estadualização da escola e pela derrubada do decreto 2.208/97, caracterizando um período de insatisfação, porém de grande mobilização interna.

Com relação à transformação de CEFET-RN para IFRN, em 2003, intensifica-se a pressão para a revogação do decreto lei para viabilizar a volta da integração ensino médio/técnico. Em 2004 acontece a derrubada do decreto 2.208/97, além da realização de várias atividades, seminários, audiências ocorridas ao longo do ano de 2003, com a participação de representantes das instituições de EPT a nível nacional. Durantes esses eventos, diversos servidores da instituição se organizaram e participaram de discussões numa ação normativa de adesão dos gestores que priorizava o fortalecimento e a expansão institucional.

Nesse contexto, por força coercitiva do governo, há a revogação do decreto 2.208/97, pelo novo decreto 5.154/04. Este último estabelece a volta da integração entre o ensino médio com o ensino técnico. E, com uma política de governo, que privilegiava a EPT, a equipe gestora, por força normativa de gestão, retoma os princípios do PPP de 95, antes ignorados, com novas reestruturações para atender às demandas instituídas pelas exigências regulamentais e socioeconômicas. Isso exigiu mais esforços e empenho dos gestores nesse processo.

\footnotetext{
${ }^{6}$ Entrevista coletada em 21.11.2009, no IFRN.
} 
A política de expansão das EPT para o interior dos estados contempla diversos municípios com novas instituições de ensino, sendo 13 no Rio Grande do Norte. Essa política permite uma melhor assistência educacional às pessoas que moram distante das capitais, incentivando tanto o desenvolvimento local dos municípios com base nas atividades produtivas. Outra contribuição seria a inserção no mercado das pessoas com limitações socioeconômicas e a sua qualificação em atividades específicas de sua região, assim, elas poderiam ingressar no mercado de trabalho sem migrarem para as capitais.

Por outro lado, essa mudança acarretou grandes desafios para a gestão, principalmente com relação à descentralização, à disseminação da cultura institucional com a expansão, à identidade institucional, à legitimidade conquistada no decorrer de sua trajetória histórica entre outros desafios. Além disso, o fato de se trabalhar com a educação básica e a qualificação dos profissionais da educação básica da rede municipal e estadual gera grandes desafios nesse processo.

Enfim, constata-se que o processo de transformação da instituição vem ocorrendo desde 1994, com avanços e recuos, caracterizando a sua convivência com a continuidade e a descontinuidade, a ordem e a desordem, característica das instituições de EPT. Isso gera, nos docentes e administrativos envolvidos nesse processo, um descompasso, pois é impossível o processo de aprendizagem humana acompanhar o desenvolvimento volátil das mudanças.

\section{A GESTÃO COM RELAÇÃO À MOBILIZAÇÃO DOS GESTORES}

Com relação à ação dos gestores no processo de mudança, percebe-se que há uma diferença no comportamento deles nos dois momentos de mudança.

\section{EM 1998 ETFRN/CEFET-RN}

O período de passagem de ETFRN para CEFET foi caracterizado por lutas dos atores institucionais pela não estadualização das escolas técnicas, em particular, a ETFRN. Para que isso não ocorresse, era necessário que a EPT oferecida por essas instituições fosse reconhecida a nível nacional, pois, nesse âmbito, só eram conhecidos os trabalhos desenvolvidos pelo SENAI, SESI, SESC e SENAC, os sistemas S. Esse movimento dos atores institucionais durou aproximadamente oito anos. A partir de 1994, uma equipe de gestores docentes e administrativos elabora o PPP, visando à reestruturação da proposta de ensino da escola e como prevenção de futuras mudanças no cenário educacional.

Em 1997, por força coercitiva do Estado, vem o decreto 2.208/97, que fez emergir na escola grande resistência por parte dos atores institucionais, não apenas na ETFRN, que virou CEFET-RN durante esse período, mas no país como um todo. No CEFET-RN, essa luta e a resistência eram mais representativas e acirradas porque a equipe havia construído o PPP com princípios completamente diferentes dos propostos pela legislação. Então, no momento em que esse projeto de reforma educacional do governo federal fazia parte da base estruturante da concepção de educação e de sociedade daquele governo, a instituição, como um todo, resiste.

Esse cenário caracteriza-se como um movimento de reestruturação pedagógica de grande resistência dentro da instituição, que via na proposta regulamentada, um aligeiramento dos cursos, com prejuízo dos conteúdos da formação geral, em benefício de uma formação instrumental para o mundo do trabalho. Esse viés evidencia a visão crítica dos gestores com relação às imposições da política de governo relativas à educação e acarreta, dentro da instituição, um movimento de resistência e de ação contrária, por parte dos gestores/atores, por não concordarem com a determinação da lei. Esse movimento demonstra, mais uma vez, a importância do comportamento dos atores institucionais no processo de implementação de mudanças institucionais.

A partir de avaliações internas, a equipe de gestores, numa ação normativa de gestão, conclui que as mudanças propostas pelo decreto 2.208/97, resultaram em sérios prejuízos à qualidade da oferta institucional de cursos técnicos, pois a prática institucional não conseguia articular as duas ofertas. Além disso, a implantação de vários 
cursos de nível superior afetava os cursos técnicos, exigindo que os gestores repensassem as suas ações administrativas e pedagógicas para não comprometerem a qualidade da oferta institucional como um todo (PPP CEFET-RN, 2003).

\section{EM 2008 - CEFET-RN/IFRN}

Com a derrubada do decreto 2208/97, dá-se o processo de expansão institucional, exigindo dos gestores muitos esforços para efetivá-la. A decisão da transformação institucional foi por força coercitiva do Estado, pois as instituições da EPT não tiveram participação ativa nas decisões, apenas foram convidadas a discutir sobre o projeto, e quem quisesse aderir se transformaria em Instituto Federal.

A mudança para IFRN é considerada uma transformação construída e pensada num âmbito estratégico, no sentido de melhorar a educação básica, não só a educação profissional, cabendo aos respectivos diretores aceitar ou não. Se aceitassem, haveria a transformação, caso contrário, a instituição continuaria como CEFET, de acordo com as determinações da lei. No entanto, esse momento histórico apresenta um diferencial com relação à mudança de 1998, ou seja, a política educacional do governo caminhava em consonância com a vontade dos gestores dos CEFET de todo o Brasil.

A partir de então, é iniciado o processo de interiorização para a educação profissional, que culminou com a sistematização da rede federal de educação tecnológica e a criação dos Institutos Federais em dezembro de 2008. Toda essa mobilização teve como perspectiva o modelo elaborado pelos CEFET, que dava boa resposta à educação profissional, baseado nos estudos relativos à educação, desenvolvidos em alguns países de primeiro mundo.

\section{A GESTÃo COM RELAÇÃO À NOVA FILOSOFIA DE GESTÃo}

Com relação à filosofia de gestão, em 1998 não se detectaram mudanças significativas nas práticas de gestão, pois a transformação institucional se deu numa dimensão mais interna, de natureza pedagógica. Porém, a mudança institucional de 2008 foi bastante representativa com relação à gestão, devido ao processo de expansão dos CEFET. No estado do Rio Grande do Norte, o CEFET-RN, a partir de 2005/2006, passa dos 4 campi, que tinha, para 11, com previsões de, até 2011, chegar a 15 campi, como afirma um gestor

A expansão da EP que teve a primeira fase, em 2005 e 2006, criando mais 56/60 escolas (na primeira fase da expansão), a rede passa de 140 para 200/202 instituições. Com a segunda fase da expansão, já passa para 354, então são 214 novas escolas, além das 140 que já existiam. E aí essa quantidade de instituições, essas novas escolas, demandava um novo modelo de gestão para essas novas escolas, uma nova institucionalidade, uma nova organização (G9) ${ }^{7}$.

Essa expansão no país e a interiorização pelos municípios demandaram uma nova filosofia de gestão, ou seja, uma gestão descentralizada, com distribuição de poderes, de autonomias administrativas. Foi uma expansão organizada, articulada e estrategicamente definida conforme os planos de atuação produtiva regional, no sentido de ter uma distribuição mais ou menos uniforme por todo o território nacional. Além disso, há, dentro da instituição, uma reestruturação e ganho de funções aliada à necessidade de um quadro suplementar de servidores para complementação dessa nova estrutura, a fim de possibilitar a oferta de cursos superiores.

A política de governo, investindo na educação profissional tecnológica e técnica, proporcionou um crescimento muito rápido às instituições CEFET em todo o Brasil, atingindo 354 unidades. Esse crescimento institucional, de certa forma, desestruturou o fazer das instituições, acarretando profundas mudanças nesse sentido. Emerge uma nova filosofia de gestão, quando nem todos os gestores haviam apreendido esse processo de mudança.

\footnotetext{
${ }^{7}$ Entrevista feita no IFRN, em 25.11.2009.
} 
Essa percepção da gestão sobre o processo de mudança demonstra a necessidade de compreender a dinâmica social com a ocorrência de imprevistos, em que a continuidade e descontinuidade são partes da trajetória evolutiva, onde todos os elementos que compõem os ambientes macro e micro se transformam por meio do surgimento do novo e, ao longo do tempo, se modificam, dando respostas no contexto no qual se inserem.

\section{CONSIDERAÇÕES FINAIS}

O cenário em que ocorrem as mudanças no IFRN, elevando-o ao patamar de um Instituto Superior de Ensino Tecnológico, é permeado por interferências de fatores intrínsecos ao ambiente institucional, principalmente até a década de 70. A partir da década de 80 , e mais propriamente de 90 , com o processo de globalização, o ambiente se amplia e novos participantes entram em cena - os fatores não institucionais. Isso ocorre devido ao desenvolvimento acelerado a partir dos anos 90, com relação ao desenvolvimento socioeconômico e das relações de trabalho em nível macro, que leva a avanços na tecnologia da informação e no conhecimento, exigindo, cada vez mais, das organizações e instituições de ensino profissional reestruturações e reorganizações da gestão e da proposta de ensino.

Inserido em um ambiente de restrições institucionais, o IFRN, ao longo de sua trajetória, tem buscado planejar e implementar ações, respondendo às forças coercitivas do ambiente macro. Em diferentes contextos sociais de sua evolução, as tomadas de decisões dos dirigentes da nação determinaram mudanças e contribuíram para o processo histórico coevolutivo, no qual se deu a prática da Educação Profissional e Tecnológica (EPT). Para atender aos pressupostos teóricos e aos objetivos do estudo, foi preciso percorrer a sua história evolutiva, conhecer os fatores que determinaram as mudanças, significando que é impossível compreender uma parte da história da EP sem considerá-la de forma articulada a um contexto maior.

As práticas isomórficas, coercitivas, normativas e miméticas permearam as ações de gestão durante toda a história do IFRN, possibilitando-lhe se desestruturar, estruturar, reestruturar e evoluir continuamente. Por intermédio dessas ações, as transformações se concretizaram e a instituição foi evoluindo. No entanto, nem todas as organizações evoluem da mesma forma, pois as variáveis que concorrem para tal são bastante diversas.

$\mathrm{Na}$ trajetória dos Institutos Federais no Brasil, as instituições se diferenciaram, ao longo do tempo, devido às diferenças ambientais externas e internas, como também as que ocorreram nas decisões e práticas de gestão, o que as faz atingir níveis de desempenho distinto. O IFRN, em 2007, foi considerado a segunda melhor instituição de EPT federal do Brasil. Esse desempenho demonstra que, em sua evolução, as mudanças são estimuladas tanto pelas mudanças ambientais, quanto pela capacidade de seus atores responderem às exigências e demandas do ambiente.

Nos dois momentos de transformações institucionais, com características diferentes, a gestão se mostrou atuante. A mudança institucional de 98 revelou a ação normativa dos gestores, que buscaram, por meio de articulações, novos empreendimentos, novos conhecimentos, novas práticas gerenciais e pedagógicas, modificações e reestruturações, para conseguirem adaptações evolucionárias, no sentido de reagir às forças coercitivas do Estado. Esse momento institucional significou para toda a comunidade a força dos gestores em busca do fortalecimento institucional, ou seja, um movimento de luta coletiva.

$\mathrm{Na}$ mudança de 2008, observa-se que a força normativa da gestão se dá no sentido de efetivação das regulamentações governamentais, advindas da política educacional de governo, favorável à expansão da rede federal de educação tecnológica pelos interiores do estado e a verticalização do ensino. Nesse contexto, o governo contou com a adesão dos atores institucionais numa ação normativa na implementação e disseminação dessa política.

Por outro lado, fica evidente a preocupação dos gestores com as novas demandas que a dimensão assumida pela nova institucionalidade acarretou, a partir da expansão, interiorização e verticalização do ensino. Tais preocupações se concretizam pela descentralização da gestão; pelo aumento da responsabilidade e carga de trabalho dos gestores e docentes; pela ampliação dos objetivos e da função social; pela diversificação da 
clientela; pelo aumento das ofertas de cursos - técnico, graduação e superior, ou seja, um crescimento tanto quantitativo quanto qualitativo da instituição.

As preocupações dos gestores também são percebidas com relação à identidade e à imagem pública da instituição, que, ao longo de sua trajetória, construiu; à preocupação em manter o padrão de qualidade do ensino ministrado com a expansão assumida; à preocupação com as novas práticas de gestão, que antes era centralizada na figura de um diretor e com relação à nova institucionalidade, que se descentraliza pelos 11 campi.

No entanto, ao mesmo tempo em há a preocupação com a dimensão assumida enquanto IFRN, constata-se um notório sentimento de comprometimento com as mudanças nas falas dos entrevistados, no sentido de que elas se efetivem com sucesso. Esse sentimento parece impulsioná-los, motivando-os para o trabalho, na busca pela sobrevivência e legitimidade da instituição pública de educação tecnológica, o IFRN.

A escolha da teoria coevolutiva foi um desafio, por se tratar de uma teoria recente e complexa, com raros trabalhos desenvolvidos no Brasil. Mas, por outro lado, a teoria conseguiu dar significado e representatividade ao estudo pelo seu caráter não linear e não determinista, de interação com os ambientes e pelo seu movimento de retroalimentação ambiental, por meio das quais as organizações, em sua evolução, estruturam-se, desestruturamse, reestruturam-se e evoluem, atendendo aos objetivos pretendidos pelo estudo.

$\mathrm{Na}$ tentativa de representar o movimento da teoria coevolutiva na evolução do IFRN, foi construída a figura a seguir,

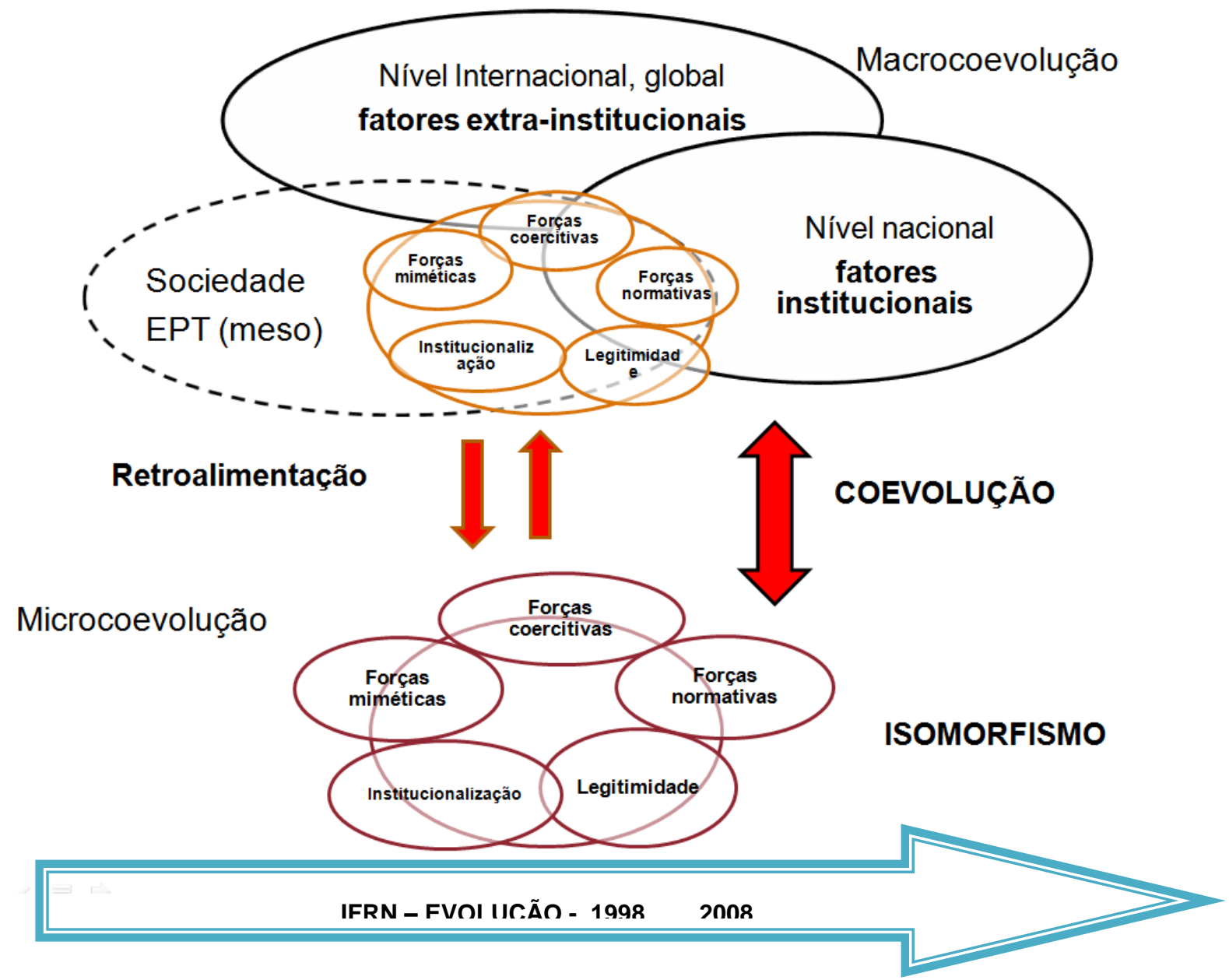

FIGURA 2: Movimento da teoria da coevolução no estudo da mudança institucional do IFRN. FONTE: dados do estudo, 2009.

A ilustração demonstra a relação de interdependência no ambiente macro entre os fatores não institucionais e institucionais e as esferas da sociedade, particularmente a EPT, em que há exigências de mudanças nesse tipo de 
ensino, a fim de atender às demandas do mundo do trabalho num contexto de uma economia globalizada. No nível micro, ocorre o mesmo processo, o IFRN, busca atender às novas exigências advindas do desenvolvimento socioeconômico e das relações de trabalho. Essas mudanças nas organizações e instituições (micro e macro) se concretizam a partir das práticas isomórficas de gestão, que no processo de institucionalização, buscam a legitimidade e acomodação institucional, o isomorfismo. As setas de posições contrárias representam a retroalimentação ambiental; a de duas pontas, o processo de coevolução. A coevolução representa o movimento de estruturação, desestruturação, reestruturação e evolução os quais vivenciam as instituições de EPT.

Nas falas dos gestores foi unânime a expressão de responsabilidade diante do quantitativo atingido pela nova institucionalidade, de 04 para 11 campi, expressando preocupação com os novos desafios para a gestão. Outro aspecto marcante em suas falas foi a presença do sentimento de grupo compartilhado pelos gestores, mesmo considerando os desafios que a expansão institucional impôs ao IFRN com a interiorização e verticalização do ensino, como também o desejo de que essa política educacional se transforme em uma política de Estado, não representando mais uma vez, uma interrupção no processo de evolução da EPT.

Portanto, o IFRN, por se inserir em um ambiente institucional de grande influência do Estado, demonstra, em suas ações, a predominância das forças coercitivas e normativas de gestão, seja em forma de adesão ou de resistência às regulamentações do governo. Porém, não se podem desconsiderar as forças miméticas, quando as instituições de EPT, como o IFRN, buscam em outras instituições de educação, novos modelos (gestão e ensino) na tentativa de superar as dificuldades e exigências que o mundo do trabalho lhes impõe. Esse contexto deixa o IFRN à mercê das regulamentações do governo, exigindo ações normativas da gestão para a implementação de novas práticas que garantam a homogeneização e legitimidade institucional.

A sua trajetória histórica apresenta-se, desde sua criação, em 1909, como Escola de Artífices, caracterizada por movimentos de interrupções em seu processo de evolução, com continuidades e descontinuidades, exigindo dos gestores, administrativos e docentes novas práticas para o atendimento às demandas do ambiente macro, advindas do desenvolvimento socioeconômico e das relações de trabalho. Ao longo dos anos, a instituição vem tentando responder às demandas do ambiente que se torna turbulento, dinâmico e complexo.

Com relação a estudos posteriores, os resultados obtidos, a partir dessa pesquisa, direcionam para diversos estudos. Seu objeto é constituído das práticas isomórficas/mudanças institucionais que são temáticas, envolvem muitas dimensões e abrangem um vasto corpo teórico de abordagens. A teoria da coevolução, por seu caráter não linear e multidimensional apresenta diversos ângulos de análise e auxilia o estudo numa perspectiva longitudinal, onde podem ser aprofundados: a questão da identidade organizacional em sua evolução; a questão da diferenciação entre instituições/organizações afins num mesmo ambiente no processo evolutivo; as implicações para a cultura organizacional no processo de evolução; o estudo da relação de interdependência entre os fatores institucionais e não institucionais e as organizações que, podendo focar elementos como, a política, as tecnologias, o avanço do conhecimento dentre outros, dão margem a outras pesquisas, em diversos campos da ciência.

\section{REFERÊNCIA}

1. BARDIN, L. Análise de conteúdo. Trad. Luís Antero Reto e Augusto Pinheiro. Lisboa: Edições 70, 2002.

2. BRASIL. MEC - MINISTÉRIO DA EDUCAÇÃO. Plano de Desenvolvimento da Educação - PDE. 2007. Disponível em www.mec.gov.br . Acesso em 10 jan. 2010.

3. CLEGG, et. al. Handbook de Estudos Organizacionais. v. 1, São Paulo: Atlas, 2006.

4. FEUERSCHÜTTE, S. G; LAMAS, Z. J.; GODOI, C. K. A Perspectiva Co-Evolutiva como Lógica de Análise das Formas Organizacionais. Disponível em: www.anpad,gov.br/enanpad/2005/ . Acesso em: $12 / 10 / 2009$.

5. FONTANELLA, B. J; RICAS, J; TURATO, E. R. Amostragem por saturação em pesquisas qualitativas em saúde: contribuições teóricas. Cad. Saúde Pública. Rio de Janeiro, 24 (1):17-27, jan, 2008. 
6. LEWIN, A. Y; LONG, C. P.; CARROL, T. N. The coevolution of the new organizational forms. Organization Science. v. 10, n. 5, p. 535-550, set./out. 1999.

7. LEWIN, A. Y; VOLBERDA, H. W. Prolegomena on coevolution: a framework for research on strategy and new organization forms. Organization Science. v. 10, n. 5, p. 519-534, Set./out. 1999.

8. LOMBARDI, J. C; SAVIANI, D; SANFELICE, J. L (orgs). Capitalismo, Trabalho e Educação. Campinas, SP: Histedbr, 2002 (coleção educação contemporânea).

9. MACHADO-DA-SILVA, C. L; FONSECA, V. S; CRUBEllate, J. M. O Processo de Institucionalização: Perspectivas na abordagem Institucionalista. TRANQUE, v. 2, n. 1, arte. 1, pág. 1-20, Jan. / junho 2005. Disponível em: www.anpad.org.br/bar . Acesso em: 25/09/2009.

10. MACHADO-DA-SILVA, C. L.; VIZEU, F. Análise institucional de práticas formais de estratégia. RAE-eletrônica Out./dez. 2007. (No corpo do trabalho, p. 7, só existe Machado.)

11. MORIN, E. Introdução ao pensamento complexo. 5 ed. Lisboa: Instituto Piaget, 2008.

12. RODRIGUES, S. B. The political dynamics of organizational culture in an institutionalized environment. Organization Studies, 27, 537-57. (2006).

13. RODRIGUES, S. B; CHILD, J. Corporate Co-evolution: A Political Perspective. Oxford: Blackwell. 2008.

14. Co-evolution in an institutionalized environment. Birmingham Business School. Journal of Management Studies, p. 40:8 December 2003a.

15. The development of corporate identity: A political perspective. Business Birmingham School. Journal Management Studies, Dez, 2003: 0022:2380.b

16. VERGARA, S. Métodos de Pesquisa em Administração. 3 ed. São Paulo: Atlas, 2007.

17. WOOD. Jr. Mudança Organizacional. 4. ed. São Paulo: Atlas, 2008.

18. YIN, R. Estudo de caso: planejamento e métodos. 3 ed. Porto Alegre: Bookman, 2005. 